\title{
Opinion: Alternative agriculture in
the Third World
}

Ricardo Henrique Silva Santos and Irene Maria Cardoso

Alternative agriculture has been attracting increased interest in the media, research centers and universities, and worldwide public opinion. So, too, non-governmental organizations of the First World have been increasing their support of alternative agriculture for underdeveloped countries, such as Brazil.

However, "alternative agriculture" may mean different things in the First and Third Worlds. We need to answer a simple and direct question: "Alternative" to what?

In a general way, the complex group of agriculture practices called "alternative" attempt to achieve several goals:

- To eliminate or decrease as much as possible the use of fertilizers and pesticides of industrial origin, thereby reducing harmful residues in the soil, groundwater, air and food;

- To preserve the chemical and biological integrity of the soil;

- To integrate diverse agricultural production processes, to recycle residues, and to reduce energy costs, using techniques such as composting, green manuring, integrated pest management, reduced tillage, and mulches;

- To produce more nutritious food.

However, these goals and practices are not an objective in their own right. The primary and fundamental purpose is to improve human living conditions through a food supply and a healthy environment in harmony with the laws that govern life on the planet. With this as the starting point, what should be done for an underdevel-

Ricardo Henrique Silva Santos and Irene Maria Cardoso are M.S. students, respectively, in Departamento Fitotecnia and Departamento Solos e Nutriçao de Plantas, Universidade Federal de Viçosa, 36570 Viçosa-MG, Brazil. oped country such as Brazil? What is the current situation to which we seek an alternative?

The following are some relevant facts about Brazil. The $90 \%$ of Brazilian farms with less than 100 ha account for only $21 \%$ of cultivated land, whereas the $0.84 \%$ with more than 1,000 ha account for $44 \%$ (IGBE, 1985). Only one-fourth of agricultural credit goes to small producers who produce about $70 \%$ of agricultural products for the domestic market; the remaining three-fourths goes to medium and large proprietors (DIEESE, 1990). Production of grain (corn, beans, rice and soybeans) fell from 63 million tons in $1988-89$ to 50 million tons in 1990-91. Three-fifths of the labor force earn a monthly salary of less then $\$ 175$, and $70 \%$ of the people are undernourished. Also, the illiteracy rate is among the highest in the world (DESER, 1991).

A holistic vision cannot disregard these facts. Clearly, most of the population has not participated in Brazilian agriculture's development spurt, and efforts to improve the quality of life of Brazilian society must concentrate on the significant portion of the population that was left out.

Besides the obvious differences in climate, soils, and technology between the First and Third Worlds, differences in the structure of society may inhibit efforts to improve the quality of life if proposals for alternative agriculture are transferred without critical analysis. Also, technology reflects the society's cultural development, and is not simply the result of mechanically applying research data.

A clear, direct example is provided by the argument for higher prices for organic products as a practical way to encourage conversion to alternative systems. This argument is valid for developed countries, where salary levels are reasonable and people have the option of choosing what kinds of products they buy. However, in Brazil the argument is immoral, because only a tiny portion of the population could afford more expensive organic products. This argument leads to elitism, excluding even more low income people from the improvement in quality of life that is the goal of alternative systems.

Given this background, significant among the many versions of alternative agriculture in Brazil is one that seeks a new agricultural paradigm that can improve the quality of life for small producers and nonlandowners. Increasingly it is being recognized that an alternative to conventional Brazilian agriculture must include redistribution of land, a reorientation of the extension and credit systems, and a major commitment of resources to scientific and technological research on low-input methods. It also must include government support to small producers for organizing and commercializing their production, and redistribution of income of urban workers to increase their purchasing power.

These needs seem largely solved in the First World, but they are crucial for those who want a holistic alternative agriculture in Brazil. On one hand, these ideas may limit the range of practices that should be proposed, making the problem even more complex. On the other hand, they hold open to the majority of Brazilian people the possibility of a better life.

\section{References}

1. DESER. 1991. Boletim No. 26, February/ March. Departamento Sindical de Estudos Rurais. Curitiba, Paraná, Brazil.

2. DIESSE. 1990. Boletim No. 111, Vol. IX, October. Departamento Intersindical de Estatística e Estudos Sócio-Econômicos. São Paolo, Brazil.

3. IBGE. 1985. Instituto Brasileiro de Geografia e Estatística. Rio de Janeiro, Brazil. 